\title{
Application of bead array technology to community dynamics of marine phytoplankton
}

\author{
Christopher K. Ellison*, Ronald S. Burton \\ Marine Biology Research Division, Scripps Institution of Oceanography, University of California, La Jolla, \\ California 92093-0202, USA
}

\begin{abstract}
Studies of the dynamics of marine microplanktonic systems have been hampered by a lack of high-throughput technologies for the simultaneous identification and quantification of the many taxa comprising such communities. To address this problem, we describe a DNA-hybridizationbased method of analysis employing bead array technology. Species- and/or genus-specific probes for 8 phytoplankton taxa were designed and applied to the microplankton community sampled from coastal waters off La Jolla, California, over an exploratory time series $10 \mathrm{~d}$ in length. Bulk DNA extractions from $1 \mathrm{l}$ of seawater were used without PCR amplification. Taxa analyzed comprised 4 dinoflagellates, 3 diatoms, and 1 coccolithophorid. The results demonstrated that specifically targeted oligonucleotide probes can be used in this fashion with a high degree of binding-specificity, dependent on hybridization temperature, and that standard curves relative to target-cell concentration can be constructed. The use of 2 different probes for each taxon can provide added confidence that probes are taxon-specific. Further, single-species assays and multiplexed assays were generally in good agreement, as were assays of replicate seawater samples. Once sets of probes are developed for particular groups of taxa, the bead array system appears to provide a technological platform with great promise for high-throughput analyses of microplanktonic communities.
\end{abstract}

KEY WORDS: Bead array · Suspension array · Phytoplankton · Community dynamics · Molecular probes $\cdot$ Molecular ecology

Resale or republication not permitted without written consent of the publisher

\section{INTRODUCTION}

Marine microplankton represent a collection of species of extraordinary taxonomic diversity and largely unknown community dynamic properties at the species level. Studies of such systems have traditionally been carried out using both light and electron microscopy with an emphasis on species identification by morphological characteristics (Miller \& Scholin 1998, Scholin et al. 1999). Light microscopy provides an excellent means of enumerating total cells in a small sample, but cannot consistently provide enough resolution of ultrastructural features for identification of many species. For example, diatoms in the genus Pseudo-nitzschia cannot be identified to the species level without scanning and transmission electron microscopy (Scholin et al. 1997). Conversely, although use of electron microscopy does allow precise taxonomic determinations, it does not permit accurate celldensity calculations (Lim et al. 1996) and is thus a largely qualitative methodology. In addition to these limitations, electron microscopy is expensive and timeconsuming and cannot be easily scaled up for analysis of the large numbers of samples required for the high spatial and temporal resolution required for analyses of community ecology.

Dynamics of a few microplanktonic species that are either bloom-producing or singularly prevalent in the world oceans have been examined using optical signatures dependent on taxonomically restricted photopigments. Perhaps the best example of such a method is the use of flow cytometry to delineate between the picoplankton genera Prochlorococcus and Synechococcus and to identify a limited number off eukaryotic 
phytoplankton having unique pigmentation (Collier 2000, Dubelaar \& Jonker 2000). In an ecological sense, flow cytometry has been applied to examine the structure of microbial planktonic communities (Gasol \& Del Giorgio 2000) and similar methods have been applied to construct total biomass estimates for certain species in the water column (Millie et al. 1997, Moreira-Turcq et al. 2001). Presently, such studies of spectral signatures are unfortunately mostly limited to a few commonly occurring planktonic species.

Increasing attention is being given to the potential of nucleic acid, antibody and lectin-binding probes for the detection and quantification of marine microplankton communities (Bates et al. 1993, Costas \& Rodas 1994, Lim et al. 1996, Tyrrell et al. 1997, Rhodes 1998, Jochem 2000). The theoretical framework for such analyses is derived from the strong binding-specificity of both complementary nucleic acid sequences and antibody:antigen pairs. Given this specificity and sufficient knowledge of the targeted organisms, probes can be designed for any taxonomic level such that they are complementary to a nucleic acid sequence or a cellsurface protein and will exclude all other non-complementary targets (Bains 1994). There are 2 principal modes of analysis: assays based on extracted nucleic acids and assays utilizing fixed whole cells (Tyrrell et al. 1997). In a broad sense, the former includes the more recently developed techniques of sandwich hybridization (Scholin et al. 1997), molecular beacons (Tyagi \& Kramer 1996), and specifically targeted fluorescent oligonucleotides (Adachi et al. 1996), while the latter is more dependent on the various methods related to fluorescent in situ hybridization (FISH) for visualization of the desired taxa (Bates et al. 1993, Lim et al. 1996, Vrieling \& Anderson 1996).

Molecular assays to detect planktonic organisms have created new opportunities for researchers seeking to investigate a single set of organisms living within a complex biotic assemblage by allowing detection of targeted individuals even at very low concentrations (Vrieling \& Anderson 1996). Further, these techniques have the ability to discern targeted individuals that have been phagocytized or that are bound to other particles in a manner that would mask their presence using traditional epifluorescence techniques (Scholin et al. 1997). Despite this, there are problematic aspects to these methods at their current level of development. For instance, when the targeted organisms are in very low abundance, quantitative analysis can become more difficult due to a scarcity of fluorescently labeled individuals on a sample filter. Additionally, fluorescent probes often have a binding affinity to both organic and inorganic debris caught and retained on a filter, returning false positive signals that can easily be misinterpreted to indicate the presence of a targeted cell (Miller
\& Scholin 1998). Finally, opportunities to simultaneously probe for multiple taxa are limited by the number of different fluorophores that can be distinguished by available equipment (typically no more than 4 ).

DNA microarrays offer an alternative technology allowing massive multiplexing. Sample DNA or cDNA can be labeled with a single fluorophore and hybridized to an array wherein each probe is assigned a specific location. Although studies utilizing this technique permit the simultaneous measurement of sample hybridization for thousands of probes, it is not particularly efficient for the analysis of many environmental samples where each sample may require a separate slide and each slide requires significant processing. Another difficulty of microarrays is that changing or adding a particular probe requires reprinting the entire array, a process limiting flexibility and likely to impede optimal probe design.

Here we explore the application of a new technology, known as bead arrays (or fluid arrays or suspension arrays), which use specific probes attached to microspheres (beads) instead of a flat surface, as in microarrays. The microspheres can be purchased in 100 machine-readable fluorescent colors for the Luminex xMAP platform used in this study, and each can be bound to a unique molecular probe so that up to 100 different probes can be employed in a single assay. As with microarrays, bulk genomic DNA can be labeled with a single fluorophore and hybridized simultaneously with a set of different probes (Ye et al. 2001). Bead array technology employs a flow cytometer to draw up the thousands of microspheres used in each hybridization (hundreds of each bead color/probe combination) and individually determine 2 fluorescent signals from each: (1) the microsphere color, which identifies the probe; (2) the fluorescent intensity of the reporter fluorophore, attached to that bead via hybridization of fluorescently labeled DNA, which quantitatively informs as to the presence of specifically targeted DNA in the sample. Two properties of this approach are particularly attractive for use in analyses of microplankton communities: (1) Taxon-specific probes are attached to microspheres in separate reactions so that one can subsequently select the set of probes to be employed for any given assay; this flexibility allows rapid changes when deciding which probes are of greatest interest to a particular analysis. (2) The analysis platform permits high samplethroughput, as commercial instruments operate in a microplate format and are capable of analyzing 96 samples, each with up to 100 probes, in less than $2 \mathrm{~h}$.

Herein, we demonstrate this system to be effective in detecting biotin-labeled bulk genomic DNA extracted from filtered seawater using capture probes specific to several genera and species of phytoplankton common in Southern California coastal waters. 


\section{MATERIALS AND METHODS}

Sample collection. We collected 10 surface seawater samples at 08:30 h once daily from the Scripps Institution of Oceanography Pier in La Jolla, California, USA from October 22 to 31, 2003. Each of these samples was collected in duplicate 11 volumes and labeled as either Series A or B. All samples were concentrated onto $5 \mu \mathrm{m}$ polycarbonate filters (Millipore) and stored at $-80^{\circ} \mathrm{C}$ in extraction buffer (DNeasy® Tissue Kit, Qiagen) until all samples had been collected.

Cultures of the dinoflagellates Lingulodinium polyedrum and Scrippsiella trochoidea were used to relate observed fluorescent output to initial cell concentrations as well as for a series of probe binding-specificity experiments. Cell concentrations were determined on a hemocytometer under $400 \times$ magnification using light microscopy. Cultured cells were then collected in known quantities by filtration.

Extraction of nucleic acids. Bulk DNA was extracted from filters using a DNeasy ${ }^{\circledR}$ Tissue Kit (Qiagen) following the protocol set out by the manufacturer. Final elution of genomic DNA concentrated the product into $100 \mu \mathrm{l}$ deionized water. Genomic DNA extracted from environmental sample filters was quantified using spectrophotometric methods (absorbance at $260 \mathrm{~nm}$ ) and diluted to a uniform concentration of $15 \mathrm{ng} \mathrm{\mu l}^{-1}$ across all samples to ensure that sample concentrations fell within the dynamic range of the labeling system (see 'Biotin-labeling of genomic DNA'). Following extraction of nucleic acids from pure culture samples of Lingulodinium polyedrum and Scrippsiella trochoidea, serial dilutions of the pure culture genomic DNA extract were assumed to represent proportional dilutions of cell concentration in a linear relationship.

Capture-probe design. Table 1 summarizes the eight 25-mer oligonucleotide probes, designed for phytoplankton taxa commonly found in nearshore waters of the Southern California Bight (M. Latz \& L. Busse pers. comm.). Additionally, a second set of probes was designed for each of these taxa as a means of cross-checking the binding-specificity of the original probes. These species and genera comprise 3 broad taxonomic groups of phytoplankton: diatoms (Bacillariophyceae), dinoflagellates (Dinophyceae), and coccolithophorids (Prymnesiophyceae). All capture probes were designed to be complementary to a por- tion of the 18S rDNA sequence for the appropriate taxon, as archived online at GenBank (www.ncbi. nlm.nih.gov). To help assure that the capture probes would have little binding affinity for one another, pair-wise comparisons were made between all oligonucleotide probes within each of the 2 probe sets and any capture probe with a complementary region to any other probe exceeding 6 base pairs in length was discarded. Finally, all probes were synthesized with a 5' C6-amino linker modification to facilitate their coupling to unique sets of Luminex xMAPTM microspheres (Luminex) having surface carboxyl-binding sites.

Oligonucleotide coupling to microspheres. Oligonucleotide capture probes were coupled to their respective microspheres (Table 1) following the protocol set forth by Yang et al. (2001). Luminex xMAPTM bead stocks were sonicated using a Branson Ultrasonic Cleaner (Branson) at $40 \mathrm{kHz}$ for $1 \mathrm{~min}$ to ensure an even distribution of beads in solution prior to being aliquoted. Fresh solutions of the primary reagents were prepared prior to each coupling reaction, including 0.1 M MES, pH 4.5 (2-[N-morpholino]ethanesulfonic acid), $0.1 \%$ (w/v) SDS (sodium dodecyl sulfate), $0.02 \%(\mathrm{v} / \mathrm{v})$ Tween ${ }^{\circledR}-20$ (polyoxyethylene-20-sorbitan monolaurate), and $10 \mathrm{mg} \mathrm{ml}^{-1}$ EDC (1-ethyl-3-[3dimethylaminopropyl] carbodiimide $\mathrm{HCl}$ ) (all from Sigma).

Table 1. Phytoplankton capture probes. Oligonucleotide sequences written in $5^{\prime}$ to $3^{\prime}$ orientation. Numbers 1 and 2 refer to different sets of capture probes designed to target same gene in the relevant taxa. Taxa without species-specific nomenclature indicate probes known to hybridize to multiple congeneric species. Bead pairing refers to specific XMAP ${ }^{\mathrm{TM}}$ microsphere colors as designated by Luminex. GenBank Accession nos. are listed below each taxon name

\begin{tabular}{|lcc|}
\hline Phytoplankton taxon & \multicolumn{1}{c}{ Probe sequence } & Bead pairing \\
\hline Diatom capture probes & & \\
Chaetoceros didymus & 1 gatgctttggtcttgtctgcactg & 123 \\
(X85392) & 2 caggatgggcaagatgcttttggtc & 147 \\
Eucampia spp. & 1 cctgttcggcagtgtcatggtgat & 143 \\
(X85389) & 2 cgtgctaacatatccaacctttgg & 157 \\
Grammatophora spp. & 1 cagtgtgcaggtacttggttgtctc & 127 \\
(AF525656) & 2 tgagatagggcttcggtactatttt & 110 \\
Dinoflagellate capture probes & \\
Ceratium furca & 1 tatgctcaatgccttgcttacat & 120 \\
(AJ276699) & 2 atgctgcatgattgattttaaacga & 113 \\
Ceratium fusus & 1 acacaaacctgaccttcaagtatgg & 140 \\
(AF022153) & 2 tcaataaccttagcttacatggata & 177 \\
Lingulodinium spp. & 1 tgcttgcacatagtgaaactgcgac & 150 \\
(AF274269) & 2 gttataggtttactggttgaccatt & 154 \\
Scrippsiella spp. & 1 accgaatgaatcgcattgcatcagc & 130 \\
(U52357) & 2 tacagtttattgatggtcattcct & 138 \\
Coccolithophorid capture probes & \\
Emiliania huxleyi & 1 gcactcaacgagtctatcacctga & 173 \\
(AF184167) & 2 gagttcccgactcacggagggatgt & 160 \\
\hline
\end{tabular}


Biotin-labeling of genomic DNA. For analysis using a bead array platform, DNA samples were directly labeled with biotin as a means of binding the reporter fluorophore, streptavidin-conjugated phycoerythrin (R-PE) during the final stages of detection and quantification. A series of dilutions of genomic DNA from the pure cultures having a known range of starting DNA concentrations were labeled. For each sample to be assayed, $20 \mu \mathrm{l}$ of diluted genomic DNA solution was used with a BioPrime ${ }^{\circledR}$ DNA labeling kit (Invitrogen Life Technologies) for biotinylation to a final volume of $55 \mathrm{\mu l}$. This kit makes use of the Klenow fragment of DNA polymerase, random octamer oligonucleotide primers, and biotin-labeled dCTP. There are several advantages to using such a system for labeling of nucleic acids: (1) random octamer primers ensure that the heterogeneous mix of genomic DNA extracted from filtered seawater will be uniformly labeled; (2) bulk genomic DNA is fragmented by the action of Klenow, reducing any inhibitory steric effects that might result from assaying untreated genomic DNA; (3) use of labeled dCTP, as opposed to labeled primers, ensures a greater number of binding sites for R-PE on the sequence of interest and, thereby, a stronger signal. However, the Klenow labeling reaction results in net DNA synthesis that may not be directly proportional to the amount of template put into the reaction. To normalize between reactions, all environmental

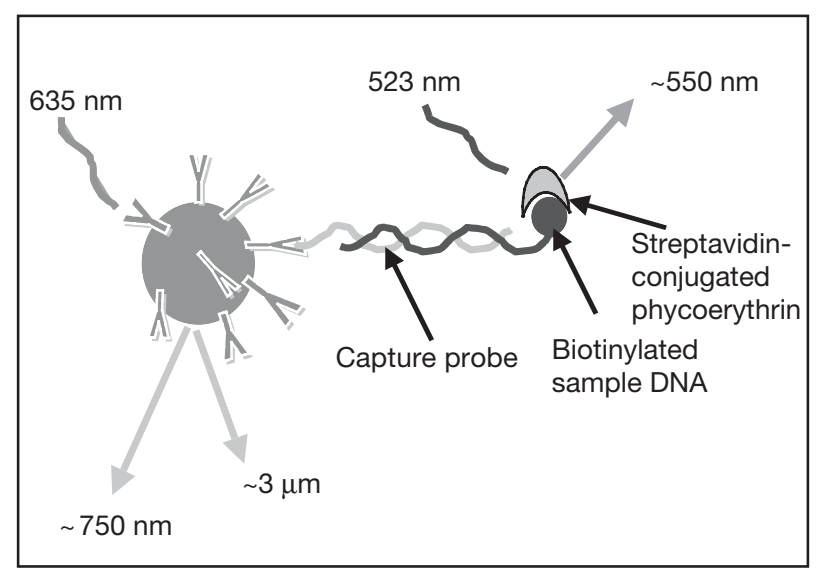

Fig. 1. Schematic diagram representing structure complex of microsphere, capture probe, biotinylated target DNA, and phycoerythrin. Excitation lasers are represented by arrows striking microsphere (left) and phycoerythrin (right). Fluorescent signal is represented by straight arrows being emitted by the microsphere and phycoerythrin (adapted from Vignali 2000). For simplicity, a single capture probe is shown bound to microsphere; in reality, the surface of the microsphere binds many capture-probes. Also, labeled sample DNA contains many biotinylated sites that are able to bind streptavidin-conjugated phycoerythrin, although only 1 is shown. The figure is not to scale samples were diluted so that a uniform $300 \mathrm{ng}$ of template was used per labeling reaction.

Bead array apparatus. The Luminex100 is a flow cytometer utilizing 2 lasers: a $635 \mathrm{~nm}$ diode laser for excitation of red and infrared classifier fluorochromes in unique ratios within 100 different bead sets, and a $532 \mathrm{~nm}$ frequency-doubling Nd-YAG laser for excitation of a reporter fluorochrome (Earley et al. 2000). These lasers serve to classify the target and to quantify its fluorescence, respectively. Oligonucleotide capture probes complementary to the target sequence are bound to the bead surface by way of attached carboxyl groups and hybridized to biotin-labeled target sequences, which can, in turn, be bound to R-PE, the reporter fluorophore. The operation is summarized in Fig. 1.

Hybridization of microspheres to sample DNA. Aliquots of the biotinylated samples (75 ng DNA in $5 \mu \mathrm{l}$ solution) were diluted to $20 \mu \mathrm{l}$ in $1.5 \mathrm{ml}$ polypropylene tubes using DNA-grade water and then denatured for $10 \mathrm{~min}$ at $95^{\circ} \mathrm{C}$. During this time interval, oligonucleotide-coupled microsphere stock-solutions were sonicated for $30 \mathrm{~s}$ at $40 \mathrm{kHz}$ and aliquoted into a working solution containing 10000 of each microsphere color selected for the assay $(0.2 \mu \mathrm{l}$ capture-probecoupled bead solution) diluted to a final volume of $40 \mathrm{\mu l}$ with $4.5 \mathrm{M}$ tetramethyl ammonium chloride (TMAC) hybridization buffer $(0.1 \%$ SDS, $50 \mathrm{mM}$ TrisCl, 4 mM EDTA, pH 8.0, after Yang et al. 2001) for each sample. This working solution was sonicated again for $30 \mathrm{~s}$ prior to adding $40 \mu \mathrm{l}$ to each of the denatured samples. Unless otherwise indicated, all samples were allowed to hybridize for exactly $2 \mathrm{~h}$ at $45^{\circ} \mathrm{C}$.

Data collection. Upon removal from the hybridization bath, the samples were centrifuged for 2 min at $13000 \times g$ using a benchtop centrifuge (Beckman Coulter) to pellet the microspheres. The supernatant was removed and the microspheres were washed with $50 \mu \mathrm{l}$ 3 M TMAC hybridization buffer to remove unbound DNA. Tubes were briefly mixed, then centrifuged again to reform the pellet. This washing step was repeated twice before adding $50 \mu \mathrm{l}$ of a final solution containing $3 \mathrm{M}$ TMAC hybridization buffer and $10 \mathrm{ng} \mathrm{\mu l}^{-1} \mathrm{R}-\mathrm{PE}$ (Qiagen). After vortexing briefly, the solution was incubated at room temperature for $10 \mathrm{~min}$ in the dark to allow binding of R-PE and incorporated biotin.

Samples were loaded into an unskirted 96-well PCR plate (Fisher Scientific) for analysis using the full $50 \mu \mathrm{l}$ volume of each sample, and placed into a Luminex 100 instrument outfitted with an XY platform. The mean fluorescence was determined for each of the probes selected for an assay using Luminex data collector software (Version 1.7). A negative control containing no DNA was included with each set of samples as a reference. 


\section{RESULTS}

\section{Fluorescent signal variability}

Identical volumes of a single genomic DNA sample are expected to yield identical fluorescent output following steps for biotin-labeling, hybridization to microspheres, and quantification on the instrument. The ability to directly compare results from different samples is dependent on such consistency of instrument operation and sample preparation. The effects of these 2 broad sources of error were partitioned to evaluate the relative importance of each. To establish the degree of signal variability inherent in the operation of the instrument, a single environmental seawater sample was prepared for analysis as described in 'Materials and methods', and then aliquoted into 5 hybridization reactions for final analysis. Each of these identical samples was analyzed with probes for all 8 taxa in a multiplexed format assaying for all 8 probes in Bead Set 1 simultaneously. Coefficients of variation were determined for the replicate analyses; the results are summarized in Table 2. Briefly, all 8 probes had a coefficient of variation less than $7.5 \%$, with the mean across all taxa being $4.8 \%$. The results also indicated that fluorescent output for a sample was best represented as a mean of multiple assays of that sample, so all further samples were assayed in triplicate and the data presented as a mean value for each probe in that sample.

Error in the sample preparation process was evaluated through the analysis of duplicates for each of the 10 environmental samples, paired by collection date. To evaluate the reproducibility of the fluorescent signal, these samples were prepared in parallel and assayed using probes for all 8 taxa in a multiplexed format. Comparisons were made across all 10 samples with respect to each probe, using a correlation between Samples A and B. The results, presented as $\mathrm{r}^{2}$ coefficients of determination, are summarized in Table 3. Positive correlations were observed for all assayed taxa, with very high values being observed in 7 of the taxa. These results indicate that inconsistencies in sample preparation play a relatively minor role in the final observed result.

\section{Cell concentration}

Biotin-labeled samples of DNA from pure cultures of Lingulodinium polyedrum and Scrippsiella trochoidea representing a range of initial cell concentrations were assayed using the respective probe in isolation (as opposed to multiplexing). The results are summarized in Fig. 2 and represent a standard by which to relate
Table 2. Coefficient of variation, CV (standard deviation divided by mean) for each taxon calculated from fluorescent output from 5 identical environmental samples. Mean coefficient of variation $=4.80 \%$

\begin{tabular}{|lcc|}
\hline Taxon & Mean fluorescence & CV (\%) \\
\hline Ceratium furca & 110.4 & 7.16 \\
Ceratium fusus & 258.9 & 3.97 \\
Lingulodinium spp. & 89.1 & 2.40 \\
Scrippsiella spp. & 134.7 & 2.63 \\
Chaetoceros didymus & 273.5 & 5.65 \\
Eucampia spp. & 967.8 & 6.62 \\
Grammatophora spp. & 56.7 & 6.41 \\
Emiliania huxleyi & 149.7 & 3.57 \\
\hline
\end{tabular}

fluorescent signal with initial sample target-cell concentration. In the case of $L$. polyedrum samples, the

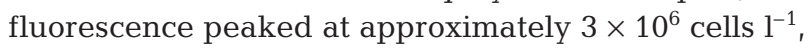
and then decreased precipitously with increasing numbers of cells. This is likely attributable to the efficiency of the Klenow biotin-labeling reaction at these high DNA concentrations. If sample DNA is too concentrated to be completely biotinylated by this reaction, then a portion of the sample will remain unlabeled and effectively serve as a binding competitor during hybridization to the appropriate capture probe. This maximum corresponded to an initial genomic

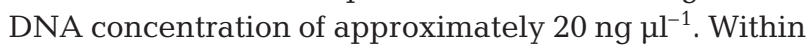
the dynamic range of the system, however, a consistent relationship between fluorescent output and cell concentration was observed. After subtraction of the blank from each sample, the relationship for the Lingulodinium spp. probe was: $Y=49.443(\log X)^{2}-55.287$ $(\log X)+1.466$ (where $Y=$ fluorescence and $X=$ cell number). For Scrippsiella spp., the relationship was: $Y$ $=40.294(\log X)^{2}-101.31(\log X)+16.72$. Coefficients of determination for the relationships were 0.95 and 0.94 , respectively. Because these values were based on biotin-labeling of a set of serial dilutions of a single

Table 3. Correlation of fluorescent output for samples collected in duplicate (A and B) and prepared and assayed in parallel. Summary data given as $\mathrm{r}^{2}$ coefficients of determination calculated separately for each taxon using 10 environmental samples

\begin{tabular}{|lc|}
\hline Taxon & $\mathrm{A}: \mathrm{B}\left(\mathrm{r}^{2}\right)$ \\
\hline Ceratium furca & 0.924 \\
Ceratium fusus & 0.954 \\
Lingulodinium spp. & 0.950 \\
Scrippsiella spp. & 0.743 \\
Chaetoceros didymus & 0.934 \\
Eucampia spp. & 0.966 \\
Grammatophora spp. & 0.565 \\
Emiliania huxleyi & 0.843 \\
\hline
\end{tabular}




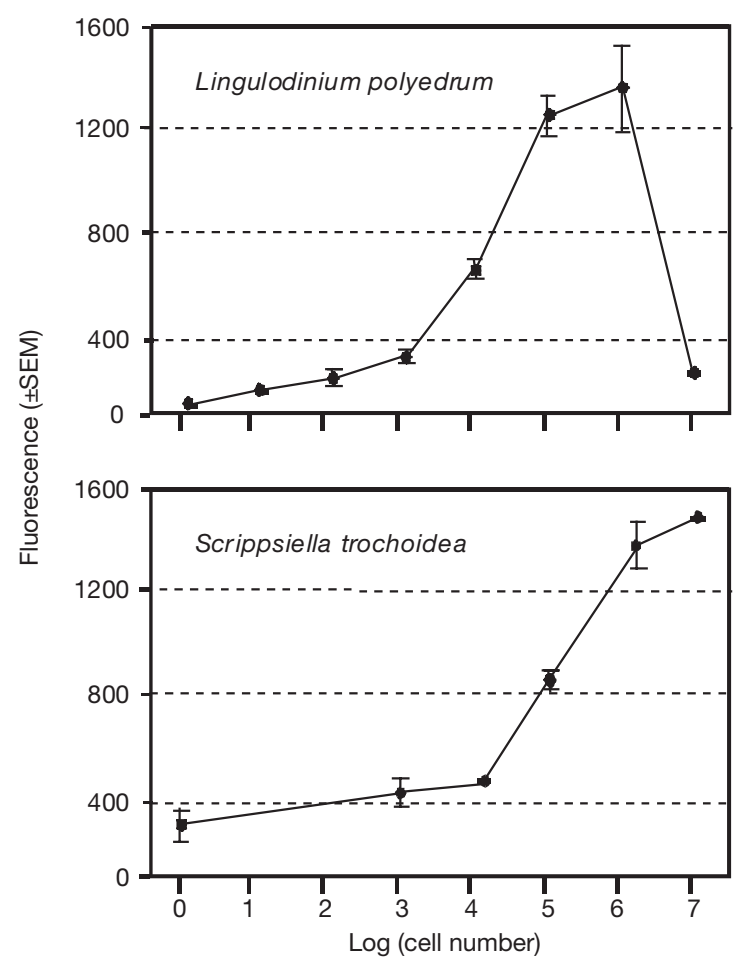

Fig. 2. Lingulodinium polyedrum and Scrippsiella trochoidea. Standard curves for fluorescence versus cell count. Measurements ( $\mathrm{N}=3$ per sample) were made using serial dilutions of DNA extracted from a known number of cells; diluted samples were then biotinylated and processed separately. Means $\pm 1 \mathrm{SE}$

DNA extraction from each species, they do not take into account potential differences in extraction efficiency that might result when cell concentrations vary or labeling efficiency when DNA content is not the same in all samples. Given these caveats, it appears that the protocols and instrumentation can reliably detect the DNA extracted from approximately 2000 to 10000 cells.

\section{Probe-specificity tests}

We biotinylated 5 each of the original environmental samples, the environmental samples with added Lingulodinium polyedrum DNA, and the environmental samples with added Scrippsiella trochoidea DNA and assayed them using Probe Set 1 for all 8 taxa in multiplexed format. The observed change in signal between environmental and spiked samples was computed for each of the probes when spiked with either $7.5 \mathrm{ng}$ of $L$. polyedrum or $6.5 \mathrm{ng}$ of $S$. trochoidea DNA. The results are summarized in Table 4 as mean change in fluorescent output over the 5 samples for each of the probes with both treatments. Although minor non-specific binding was observed with increased DNA concentration in the assay, only the probe targeting the spiked DNA clearly showed highly significant increases in both cases.

\section{Signal-to-noise ratio}

Oligonucleotide probes are expected to bind their complement with greater sequence specificity at temperatures nearing their respective melting temperatures $\left(T_{\mathrm{m}}\right)$ and less specifically (but more strongly) at lower hybridization temperatures. In the context of the bead array system, lower hybridization temperatures provide a maximum signal, but at the cost of increased background noise. We tested the parameters of these binding kinetics using labeled DNA isolated from the 2 pure cultures. The genomic DNA was combined in 5:0, $4: 1,1: 1,1: 4$, and $0: 5$ ratios of Lingulodinium polyedrum: Scrippsiella trochoidea, all having a constant final DNA concentration. These were labeled with biotin and assayed using probes for all 8 taxa in multiplexed format with hybridization temperatures of 45 , 50,55 , and $60^{\circ} \mathrm{C}$. The results for 45,50 and $55^{\circ} \mathrm{C}$ are presented in Fig. 3; fluorescence values are reported as corrected fluorescence to indicate that background measured with a negative control sample containing no DNA has been subtracted from the raw fluorescence values. At $60^{\circ} \mathrm{C}$, none of the probes were able to successfully bind any labeled DNA in solution, and the fluorescent signal was negligible. With decreasing hybridization temperature below this point, signal strength of the Lingulodinium spp. and Scrippsiella spp. probes increased, as did the gradual background signal of other probes binding non-specifically. At $45^{\circ} \mathrm{C}$, the corrected fluorescence values for the Lingulodinium spp. and Scrippsiella spp. probes were virtu-

Table 4. Results of sample spiking experiment. Data are presented as mean increase in observed fluorescent output across 5 samples for each of the taxa when spiked with DNA from pure culture samples of the species indicated

\begin{tabular}{|c|c|c|}
\hline \multirow[t]{2}{*}{ Probe } & \multicolumn{2}{|c|}{ Sample DNA added } \\
\hline & $\begin{array}{l}\text { Lingulodinium } \\
\text { polyedrum }\end{array}$ & $\begin{array}{c}\text { Scrippsiella } \\
\text { trochoidea }\end{array}$ \\
\hline Ceratium furca & 4.8 & 14.2 \\
\hline Ceratium fusus & 4.5 & 0.8 \\
\hline Lingulodinium spp. & 117.6 & 4.7 \\
\hline Scrippsiella spp. & 5.8 & 84.0 \\
\hline Chaetoceros didymus & 1.9 & 5.1 \\
\hline Eucampia spp. & 4.9 & 9.4 \\
\hline Grammatophora spp. & 6.2 & 3.3 \\
\hline Emiliania huxleyi & 8.7 & 2.0 \\
\hline
\end{tabular}


a) $45^{\circ} \mathrm{C}$ hybridization

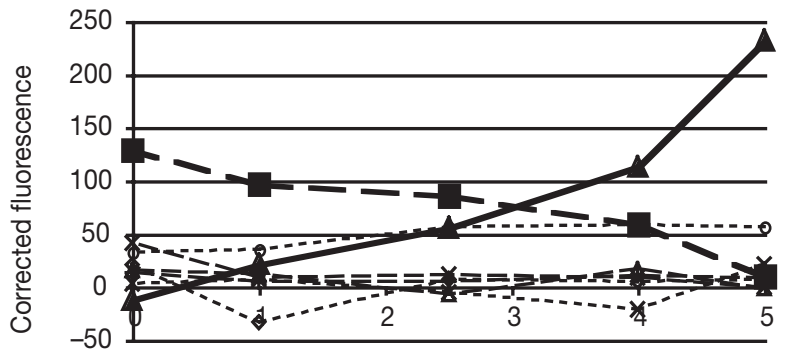

b) $50^{\circ} \mathrm{C}$ hybridization
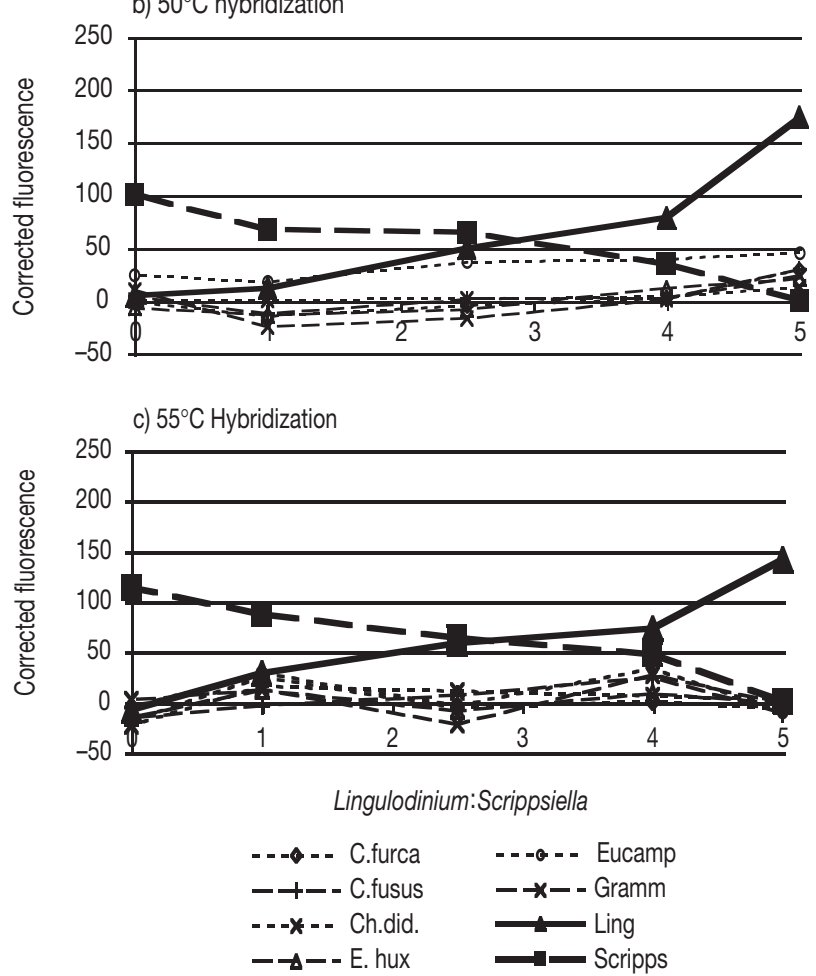

Fig. 3. Lingulodinium polyedrum and Scrippsiella trochoidea. Fluorescent signal observed across 3 different hybridization temperatures. At all temperatures, concentration of $L$. polyedrum target-sequence decreases and concentration of $S$. trochoidea decreases from left to right across the graphs. Maximum signal strength is at $45^{\circ} \mathrm{C}$ (a), although noise observed in other probes is also reasonably high; (b) and (c) show a small decline in signal strength associated with increased bindingspecificity as hybridization temperature is increased

ally identical to those values predicted by the standard curves that had been generated for these targets (see Fig. 2). One probe, targeted to Eucampia spp., increased most noticeably, although in a uniform fashion that indicated no preferential binding to either $L$. polyedrum or $S$. trochoidea. Further, the signal for the Eucampia spp. probe was very small relative to the signal observed for Lingulodinium spp. and Scrippsiella spp. probes.

\section{Environmental sample analysis}

All 10 environmental samples were assayed using probes for each of the taxa in a multiplexed format. The corrected fluorescence was then adjusted according to the dilution factor that had been used on each sample prior to biotin-labeling, and is plotted with respect to time in Fig. 4. The samples were collected during the final stages of a phytoplankton bloom, as is evident from the rapid decline through time for several of the taxa. Other taxa did not follow this general pattern, however. Most notably, Emiliania huxleyi, which can be smaller than our $5 \mu \mathrm{m}$ filter size, remained at a constant very low level over the entire course of the time series. Others, such as Lingulodinium spp., appeared to have a small secondary peak that was unique to that probe.

For the 2 species for which we had been able to establish standard curves relative to sample cell concentrations, Lingulodinium polyedrum and Scrippsiella trochoidea, the corrected fluorescence values were adjusted to indicate changes in cell concentration in the samples over time. These data are summarized in Fig. 5. Note that the apparent absence of cells for the

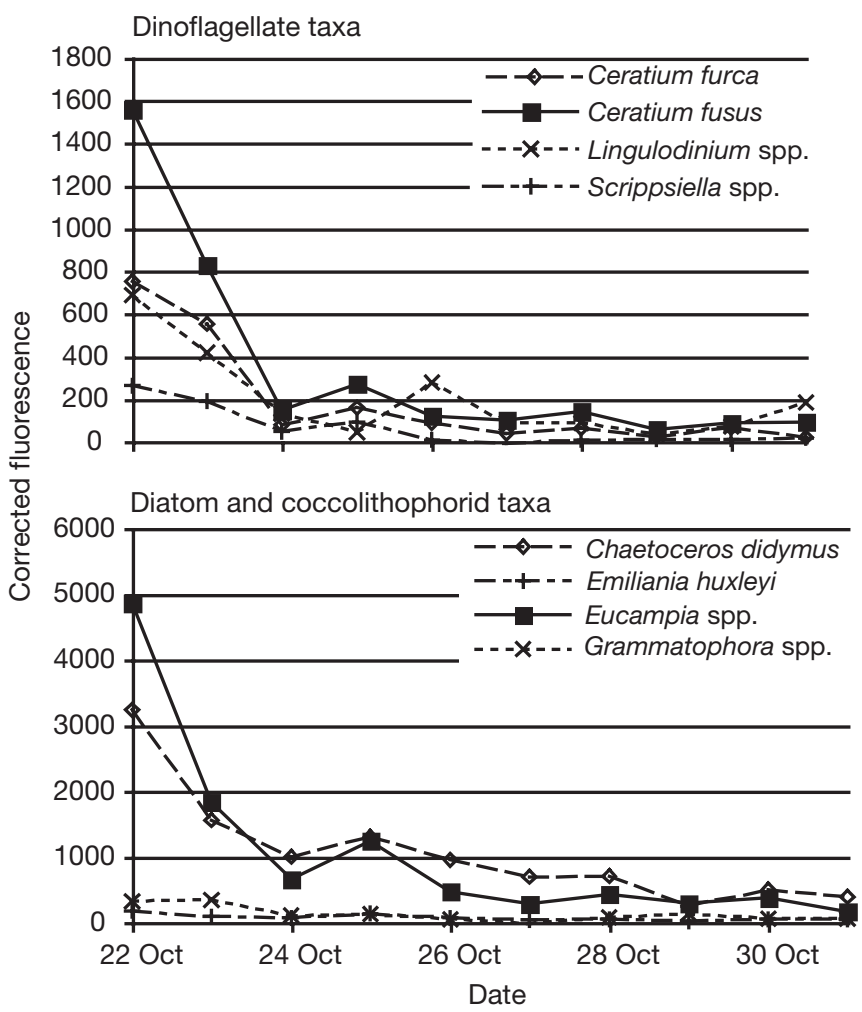

Fig. 4. Fluorescent output over course of the sampling series, divided taxonomically into dinoflagellates and diatoms/ coccolithophorids. Sampling began at end of a pronounced bloom in coastal waters of La Jolla, California, which is reflected in the rapid decrease in signal over the first few days of the time series 
Table 5. Coefficient of determination $\left(\mathrm{r}^{2}\right)$ values showing the comparison of data collected on 10 environmental samples using 2 sets of capture probes targeting the same selection of taxa

\begin{tabular}{|lc|}
\hline Taxon & $1: 2\left(\mathrm{r}^{2}\right)$ \\
\hline Ceratium furca & 0.999 \\
Ceratium fusus & 0.971 \\
Lingulodinium spp. & 0.997 \\
Scrippsiella spp. & 0.997 \\
Chaetoceros didymus & 0.995 \\
Eucampia spp. & 0.999 \\
Grammatophora spp. & 0.992 \\
Emiliania huxleyi & 0.860 \\
\hline
\end{tabular}

majority of the time series is probably due to a combination of scale and passing below the detection limits of the technique. For some samples with small, positive, calculated cell concentrations during the latter part of the time series, their appearance is dwarfed by earlier samples with concentrations several orders of magnitude higher than those near the end. Other samples, specifically many of those for the Scrippsiella spp. probe, were calculated to be zero and were, therefore, either absent from the samples entirely or present in concentrations below the detection limits of the system.

\section{Probe duplication}

Data collected for the initial environmental sample analysis were collected for all 8 taxa on the 10 environmental samples. The second set of probes, targeted to the same gene in the same taxa, was applied to these samples in a multiplexed format. While the precise intensity of fluorescent output detected is nearly

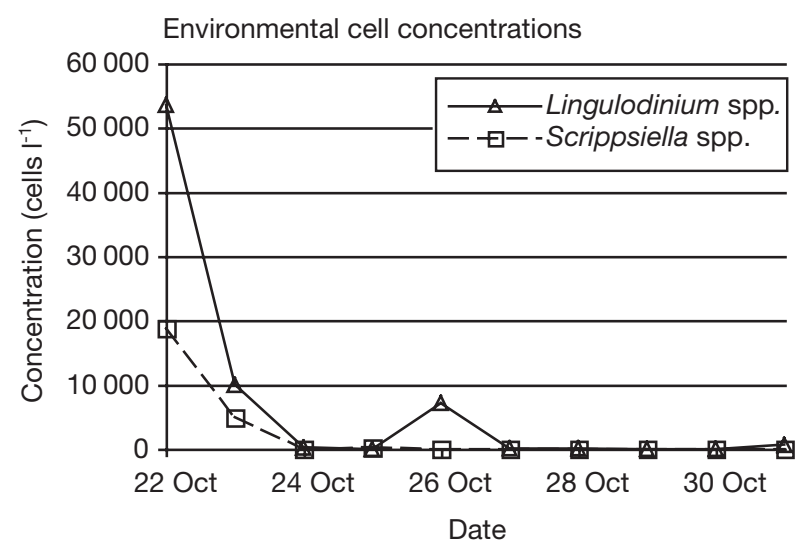

Fig. 5. Lingulodinium spp. and Scrippsiella spp. Inferred environmental cell concentrations over course of the sampling series, converted from fluorescence to cells $\mathrm{l}^{-1}$ using relationship determined from standard curves generated for each of these taxa always different between bead sets due to variations in the density of capture-probe-coupled microspheres, the gross characteristics of each sample should be similar if both probes are detecting fluctuations in the concentration of the same target. Data from probes targeted to the same taxon were compared and a coefficient of correlation was calculated for each of the taxa; these $r^{2}$ values are presented in Table 5. All 8 of the taxa demonstrated high $\mathrm{r}^{2}$ values, with 7 of 8 exceeding 0.97 , indicating that the paired probes were binding the same targets.

\section{Effects of multiplexing}

One of the principal benefits of the bead array platform is its capacity to simultaneously quantify the presence of multiple targets in a single sample. This manner of data collection is contingent on the ability of the microspheres to function autonomously in solution without interacting with different microspheres and probes. To test this independence, the 10 environmental samples were assayed using probes for all 8 taxa in a multiplexed format. The same samples were then assayed using each probe independently in solution. Results for the series of samples were compared and an $\mathrm{r}^{2}$ coefficient of determination was calculated for each probe; these values are presented in Table 6.

The same environmental samples were evaluated again using both the original and the second probe sets together in a series of 16-plex assays. Coefficients of determination were calculated for comparisons between the 2 sets of probes and are also presented in Table 6 . While these values are generally high and indicative of good correlations, the probes for Eucampia spp. and Grammatophora spp. are lower. This was possibly due to interactions of probes from different sets that had not been checked against each other prior to the 16-plex assay.

Table 6. Coefficient of determination $\left(\mathrm{r}^{2}\right)$ values showing effects of multiplex analysis on fluorescent output. High $\mathrm{r}^{2}$ values are interpreted as evidence that multiplexing does not affect data collection and that probes are not preferentially binding each other during hybridization

\begin{tabular}{|lcc|}
\hline Taxon & Single:Multiplex $\left(\mathrm{r}^{2}\right)$ & 16-plex $\left(\mathrm{r}^{2}\right)$ \\
\hline Ceratium furca & 0.985 & 0.999 \\
Ceratium fusus & 0.991 & 0.926 \\
Lingulodinium spp. & 0.982 & 0.919 \\
Scrippsiella spp. & 0.924 & 0.752 \\
Chaetoceros didymus & 0.997 & 0.930 \\
Eucampia spp. & 0.996 & 0.762 \\
Grammatophora spp. & 0.869 & 0.772 \\
Emiliania huxleyi & 0.862 & 0.883 \\
\hline
\end{tabular}




\section{DISCUSSION}

The 2 principal means of examining environmental samples of plankton communities are by morphological identification under magnification or through a variety of techniques related to optical classifications based on photopigment characteristics, including flow cytometry. Both modes of study provide an excellent view of the microscopic constituents of the plankton. Despite this, there are significant drawbacks associated with the use of either method. Microscopy-based techniques provide the clearest, diagnostic assessment of the planktonic community, but are extraordinarily time-consuming to the extent that large-scale studies involving numerous samples are all but prohibitive in scope (Miller \& Scholin 1998). A further difficulty that is often encountered is the steep learning curve associated with familiarizing oneself with the requisite taxonomy for such a study. Conversely, optical determination of photopigment concentration provides a relatively simple methodological approach allowing rapid processing times, but with limited flexibility for the fine-scale taxonomic determination of a wide range of taxa (Lauria et al. 1999). Thus, there is a significant divide between taxonomic specificity and scope of analysis in studies of the plankton.

Nucleic acid hybridization methodologies hold great promise for characterization of microplankton communities. Here, we have shown that bead array technology may provide a means of expanding current environmental sampling techniques via its potential for high-throughput sample analysis and automation. Working at capacity, the Luminex 100 instrument can be used to quantitatively assay 100 different taxa simultaneously. Samples can be analyzed in this fashion in 96-well plate format and, thus, 95 samples (plus 1 negative control) can be examined in a single run of the bead array instrumentation. Preparation time for such a sample is typically in the range of $4 \mathrm{~h}$ from the time of filtration of bulk seawater to the final operation of the Luminex 100 instrument. Similar assays have been undertaken to identify microbial targets in terrestrial aquatic systems (Spiro et al. 2000, Spiro \& Lowe 2002). This study, however, avoids the pitfalls associated with potential biased amplification via the polymerase chain reaction (PCR) by bypassing such an amplification step. In cases where presence/absence data are more important than quantitative data, a PCR amplification step may be applied to the environmental DNA sample to increase the sensitivity of the bead array technology.

Detailed population-level analyses of planktonic systems have traditionally been plagued by a reliance on techniques that are inordinately labor-intensive and difficult to perform. While establishing a bead array system to assay a community of interest requires significant time in probe development and testing, the instrument operates quickly and easily once the groundwork has been laid, allowing the assessment of many samples in a relatively quick fashion. Dynamics of many species could be examined simultaneously in a number of samples collected over an intensive spatial or temporal sampling regime. Although limited to 100 probes at a time, aliquots of a given environmental sample could be hybridized to multiple probe sets. In addition to extending the phytoplankton probe set initiated in this report, we envision developing probes to taxa occupying other trophic levels; in principle, simultaneous quantitative measurement of bacterioplankton, phytoplankton, and primary consumers such as ciliates can be achieved.

Monitoring of harmful algal blooms may prove to be an important application of bead array technology. This phenomenon is the subject of numerous studies (Stumpf 2001) and has been associated with several environmental factors, but there is still relatively little known about the mechanisms and patterns of such blooms (Babaran et al. 1998). Because of the exceptional interest in understanding the dynamics of bloom-producing phytoplankton, significant effort has also been directed toward establishing algal bloommonitoring networks in the hopes of mediating potentially harmful effects of such blooms through early detection (Schofield et al. 1999, Dubelaar \& Gerritzen 2000, Johnsen \& Sakshaug 2000, Lewitus \& Holland 2003). Of the approximately 500 species of microalgae that exist worldwide, only about 100 are toxic (Fisher et al. 2003). Using a bead array platform, one could screen environmental samples for these species as a means of monitoring a study area for incipient blooms and, with a $4 \mathrm{~h}$ processing time for such analysis, preemptive actions may be possible to minimize the potential impact on public and economic interests.

The results presented here demonstrate that bead array systems provide a robust analytical system for analyzing phytoplankton communities. Fluorescence is demonstrated to be repeatable to within $7.5 \%$, and samples can be successfully analyzed in multiplexed formats without significant loss in the ability to discern relative fluorescent output. Further, multiple controls demonstrate that most of the probes appear to bind the targeted sequence specifically, although some optimization of signal-to-noise ratio will probably be necessary for each probe set. Finally, environmental samples can be assayed for the targeted taxa and their taxon-specific cell concentrations determined using standard curves constructed from pure cell cultures or, in some cases, from environmental samples subjected to microscopic examination. 
Significant development remains to be completed before bead array technology can be widely applied to studies of plankton communities. Primarily, a groundtruthing of environmental data using morphological identification is necessary, as morphology remains, with good reason, the gold standard of taxonomy. Also, correlation of fluorescent output and cellular concentration of target organisms can most readily be established via analysis of cultured samples. Therefore, analysis of a broader sampling of cultured taxa will allow the collection of more ecologically meaningful data through the conversion of fluorescent signal to environmental cell concentration. Given analysis of a suitable number of cultured taxa, it may be possible to generalize this conversion for broad taxonomic groups to allow more rapid future probe development. For instance, the fluorescence:cell concentration correlations calculated for Lingulodinium spp. and Scrippsiella spp. were reasonably similar, indicating the possibility for a universal conversion equation for all dinoflagellates. In terms of plankton community research, it is important that further probes incorporating a diversity of trophic levels, including nanoplankton and microzooplankton, be developed to add greater perspective to future studies.

Finally, there are a number of potential modifications to currently developed protocols for bead array systems that may make their use in oceanography more tractable, both in terms of ease and cost to the researcher. For example, it may be possible to attach biotin to the targeted molecules by a sandwich hybridization method, in which a fluorophore-labeled universal oligonucleotide is allowed to hybridize to target molecules, while capture probes attach to a different, species-specific region of the same molecule. This would effectively bind the fluorophores necessary for detection and significantly reduce time and cost by eliminating the biotin-labeling step. Alternatively, the process of labeling each DNA sample with biotin may be eliminated entirely by using the genomic DNA extract as a quantitative competitor against complementary biotin-labeled oligonucleotides. In such a system, decreases in detected fluorescent output would be used to quantify the presence of targeted molecules.

Bead array technology, with its potential for rapid, high-throughput quantitative analysis, may open the door to more synoptic and comprehensive molecular analyses of diverse plankton communities. Once the painstaking process of probe development has been completed, sets of such probes can be widely employed in well-behaved multiplex format and easily compared between multiple analytical facilities in an effort to gain a greater understanding of the dynamics of marine microplankton communities.
Acknowledgements. The authors gratefully acknowledge the financial support provided by a National Science Foundation Major Research Instrumentation Grant and a University of California Academic Senate Research Grant. A Doherty Fellowship from the Scripps Graduate Department supported C.K.E. We also thank M. Latz, L. Busse, B. Palenik, and D. Landry for samples and/or helpful comments. Finally, we acknowledge the helpful comments of 3 anonymous reviewers.

\section{LITERATURE CITED}

Adachi M, Sako Y, Ishida, Y (1996) Identification of the toxic dinoflagellates Alexandrium catenella and A. tamarense (Dinophyceae) using DNA probes and whole-cell hybridization. J Phycol 32:1049-1052

Bains W (1994) Selection of oligonucleotide probes and experimental conditions for multiplex hybridization experiments. Genet Anal Biomol Eng 11:49-62

Barbaran RP, Espinosa RA, Abalos TU (1998) Initiating and triggering mechanisms causing harmful algal blooms. J Shellfish Res 17:1623-1626

Bates SS, Léger C, Keafer, BA, Anderson DM (1993) Discrimination between domoic-acid-producing and nontoxic forms of the diatom Pseudonitzschia pungens using immunofluorescence. Mar Ecol Prog Ser 100:185-195

Collier JL (2000) Flow cytometry and the single cell in phycology. J Phycol 36:628-644

Costas E, Rodas VL (1994) Identification of marine dinoflagellates using fluorescent lectins. J Phycol 30:987-990

Dubelaar GBJ, Gerritzen PL (2000) Cytobuoy: a step forward towards using flow cytometry in operational oceanography. Sci Mar 64:255-265

Dubelaar GBJ, Jonker RR (2000) Flow cytometry as a tool for the study of phytoplankton. Sci Mar 64:135-156

Earley MC, Vogt RF, Shapiro HM, Mandy FF and 6 others (2000) Report from a workshop on multianalyte microsphere assays. Cytometry 50:239-242

Fisher WS, Malone TC, Giattina JD (2003) A pilot project to detect and forecast harmful algal blooms in the northern Gulf of Mexico. Environ Monit Assess 81:373-381

Gasol JM, del Giorgio PA (2000) Using flow cytometry for counting natural planktonic bacteria and understanding the structure of planktonic bacterial communities. Sci Mar 64:197-224

Jochem FJ (2000) Probing the physiological state of phytoplankton at the single-cell level. Sci Mar 64:183-195

Johnsen G, Sakshaug E (2000) Monitoring of harmful algal blooms along the Norwegian coast using bio-optical methods. S Afr J Mar Sci 22:309-321

Lauria ML, Purdie DA, Sharples J (1999) Contrasting phytoplankton distributions controlled by tidal turbulence in an estuary. J Mar Syst 21:189-197

Lewitus AJ, Holland AF (2003) Initial results from a multiinstitutional collaboration to monitor harmful algal blooms in South Carolina. Environ Monit Assess 81:361-371

Lim EL, Caron DA, Delong EF (1996) Development and field application of a quantitative method for examining natural assemblages of protists with oligonucleotide probes. Appl Environ Microb 62:1416-1423

Miller PE, Scholin CA (1998) Identification and enumeration of cultured and wild Pseudo-nitzschia (Bacillariophyceae) using species-specific LSU rRNA-targeted fluorescent probes and filter-based whole cell hybridization. J Phycol 34:371-382

Millie DF, Schofield OM, Kirkpatrick GJ, Johnsen F, Tester 
PA, Vinyard BT (1997) Detection of harmful algal blooms using photopigments and absorption signatures: a case study of the Florida red tide dinoflagellate, Gymnodinium breve. Limnol Oceanogr 42:1240-1251

Moreira-Turcq PF, Cauwet G, Martin JM (2001) Contribution of flow cytometry to estimate picoplankton biomass in estuarine systems. Hydrobiologia 462:157-168

Rhodes WL (1998) Identification of potentially toxic Pseudonitzschia (Bacillariophyceae) in New Zealand coastal waters, using lectins. NZ J Mar Freshw Res 32:537-544

Schofield O, Grzymski J, Bissett WP, Kirkpatrick GJ, Millie DF, Moline M, Roesler CS (1999) Optical monitoring and forecasting systems for harmful algal blooms: possibility or pipe dream. J Phycol 35:1477-1496

Scholin CA, Miller P, Buck K, Chavez F, Harris P, Haydock P, Howard J, Cangelosi G (1997) Detection and quantification of Pseudo-nitzschia australis in cultured and natural populations using LSU rRNA-targeted probes. Limnol Oceanogr 425:1265-1272

Scholin CA, Marin R, Miller PE, Doucette GJ, Powell CL, Haydock P, Howard J, Ray J (1999) DNA probes and a receptor-binding assay for detection of Pseudo-nitzschia (Bacillariophyceae) species and domoic acid activity in cultured and natural samples. J Phycol 35:1356-1367

Spiro A, Lowe M (2002) Quantitation of DNA sequences in environmental PCR products by a multiplexed, bead-

Editorial responsibility: Otto Kinne (Editor-in-Chief), Oldendorf/Luhe, Germany based method. Appl Environ Microbiol 68(2):1010-1013 Spiro A, Lowe M, Brown D (2000) A bead-based method for multiplexed identification and quantitation of DNA sequences using flow cytometry. Appl Environ Microbiol 66:4258-4265

Stumpf RP (2001) Applications of satellite ocean color sensors for monitoring and predicting harmful algal blooms. Hum Ecol Risk Assess 7:1329-1345

Tyagi S, Kramer FR (1996) Molecular beacons: probes that fluoresce upon hybridization. Nat Biotechnol 14:303-308

Tyrrell JV, Bergquist PR, Saul DJ, MacKenzie L, Bergquist PL (1997) Oligonucleotide probe technology as applied to the study of harmful algal blooms. New Zeal J Fresh Res 31: 551-560

Vignali DAA (2000) Multiplexed particle-based flow cytometric assays. J Immunol Methods 243:243-255

Vrieling EG, Anderson DM (1996) Immunofluorescence in phytoplankton research: applications and potential. J Phycol 32:1-16

Yang L, Tran DK, Wang X (2001) BADGE, BeadsArray for the Detection of Gene Expression, a high-throughput diagnostic bioassay. Genome Res 11:1888-1898

Ye F, Li M, Taylor JD, Nguyen Q and 5 others (2001) Fluorescent microsphere-based readout technology for multiplexed human single nucleotide polymorphism analysis and bacterial identification. Hum Mutat 17:305-316

Submitted: March 31, 2004; Accepted: September 28, 2004 Proofs received from author(s): March 3, 2005 